\title{
Repensar la identidad artista-investigadora, desde el proyecto "Diálogos con mujeres artistas docentes"
}

\section{Rethinking the identity artist-researcher, from the project "Dialogues with women art teachers"}

\author{
M. RoSARIO GARCÍA-HUIDOBRo \\ Universidad de Barcelona \\ rosarioghm@gmail.com
}

Recibido: 30 de enero de 2014

Aprobado: 20 de enero de 2015

\begin{abstract}
Resumen
El cuestionamiento sobre la identidad y los diversos roles que los artistas han comenzado a explorar, desde el siglo pasado, son aspectos fundamentales en este artículo. Hoy es difícil seguir hablando del artista como individuo de talento innato que trabaja aislado en su taller, sino que los diversos efectos sociales, políticos y culturales, han trasladado a los artistas a ser parte del mundo social y a generar prácticas artísticas que visualicen y manifiesten críticamente estas preocupaciones. Para explicar estos tránsitos con mayor profundidad, se compartirá parte de la práctica y reflexión artística personal, y cómo ésta ha comenzado a entrelazarse con la investigación de tesis doctoral, a través del proyecto artístico "Diálogos con mujeres artistas docentes". A partir de la experiencia como artista e investigadora en formación, se comparte en qué consiste el proyecto de indagación artística y se reflexiona sus puntos de encuentro con la noción de 'práctica artística como investigación' desarrollada por Graeme Sullivan $(2010,2011)$. Por otro lado, se buscará reflexionar cómo las identidades 'artista' y 'académica' están en un constante diálogo personal. Este proyecto artístico busca mostrar que estas identidades no están en un posicionamiento fijo, más bien reflexionar, desde el lugar de un artista, cómo a través de los diversos desplazamientos por diversas disciplinas, se puede concebir un tipo de identidad 'in-between'. Esto último hace referencia a la posibilidad de comprender los procesos de ser mujer, artista e investigadora que transita y conforma su identidad entre ambas disciplinas.
\end{abstract}

Palabras clave: práctica artística, investigación académica, identidad, transitar.

García-Huidobro, M.R. (2015): Repensar la identidad artista-investigadora, desde el proyecto "Diálogos con mujeres artistas docentes". Arte, Individuo y Sociedad, 27(2) 197-211 


\begin{abstract}
The questioning of identity and the various roles that artists have begun to explore, from the last century, are fundamental aspects in this article. Today it is difficult to speak of the artist as individual isolated innate talent working in his studio, but the various social, political and cultural effects, have moved the artists to become part of the social world and to generate artistic practices that visualize and manifest critically these concerns. To explain these transits deeper, we will share part of the personal artistic practice and reflections, and how it has begun to intertwine with the doctoral research, through the art project "Dialogues with women art teachers". From the experience as an artist and researcher in training, we will share what this project of artistic inquiry is about and reflect their points with the notion of 'artistic practice as research' developed by Graeme Sullivan (2010, 2011). On the other hand, we will seek to reflect how the identities of 'artist' and 'academic' are in constant dialogue. This art project seeks to show that these identities are not in a fixed position, but rather reflect, from the place of an artist, how through the various shifts in different disciplines, can conceive an identity 'in-between'. The latter refers to the ability to understand the processes of being a woman, artist and researcher who travels and forms its identity among both disciplines. Keywords: art practice, academic research, identity, transit.
\end{abstract}

Sumario: 1. Nociones sobre la práctica artística, 1.1. Concepciones sobre la práctica artística como investigación, 2. Recorridos por la práctica artística y de investigación académica, 3. Comprender la práctica artística como investigación en el proyecto "Diálogos con mujeres artistas docentes", 3.1. El proceso de construcción de "Diálogos con mujeres artistas docentes. Elisa", 4. Transitar entre la práctica artística y de investigación. Comprender las múltiples identidades in-between, 5. Conclusiones. Referencias.

\title{
1. Nociones sobre la práctica artística
}

A lo largo de la historia han existido diversos modelos de práctica artística. Desde las academias a los cafés, desde la clase a los estudios y también al mundo virtual. Por otro lado, los roles de los artistas han cambiado con las épocas. En los inicios de la ilustración surgió la idea del artista como un analítico o un tecnólogo. Esta visión señaló que los artistas y científicos compartían como objetivo el intentar comprender cómo funciona el mundo. A mediados del siglo XX predominó la noción del artista como maestro ya que el artista era un profesional que poseía capital cultural que necesitaba ser llevado a entornos educativos (Sullivan, 2010). A partir de 1960, los revuelos sociales llevaron a generaciones de artistas a infundir la enseñanza de las artes en las escuelas bajo un nuevo sentido de libertad creativa que fomentaba a los estudiantes a explorar las artes. En los 90', bajo las críticas posmodernas, los artistas y académicos comenzaron a encarar nuevos desafíos que no podían ignorar. Los tipos de prácticas artísticas que se enseñaban y desarrollaban en las escuelas de artes y universidades comenzaron a responder críticamente a aspectos sociales, políticos y culturales que cuestionaban las nociones de identidad fija, y por ende, demandaban al artista contemporáneo a actuar como un "teórico, performer, productor, instalador, escritor, animador, y chamán” ( Sullivan, 2010:4).

En este sentido,la práctica artística comenzó a ser comprendida como un espacio crítico y creativo de investigación, que comenzó a fomentar, desde nuevas 
perspectivas, nuevas formas de pensar y comprender nuestras vidas. Desde aquí, Sullivan (2010) ha señalado tres tipos de prácticas artísticas.

1. Hacer en Sistemas. Corresponderían al tipo de prácticas en que los artistas están interesados en reconfigurar y generan nuevas formas visuales de representación que trasciendan a las disciplinas de conocimiento establecidas. Buscan romper sus límites para intersectarse con otras perspectivas o áreas. Existe un deseo por utilizar las disciplinas del conocimiento como base de investigación, las cuales al interactuar y ser entrelazadas, muestran nuevas formas de conceptualizar las formas y estructuras visuales.

2. Hacer en Comunidad. Estas prácticas utilizan la capacidad comunicativa de las artes visuales para crear nuevas conexiones entre ideas personales y públicas. El artista, "como un trabajador cultural", utiliza su práctica visual con comunidades artísticas, para generar nuevas comprensiones.

3. Hacer en Cultura. Corresponde al tipo de prácticas artísticas que se generan en espacios interculturales. Desarrollan una práctica artística crítica e investigan nuevas formas de fomentar encuentros visuales y el conocimiento humano. Utilizan sus experiencias híbridas, de haber crecido y trabajado en diversos países y culturas como base para su experiencia imaginativa e intelectual, para comprender cómo otorgamos significados a las diversas imágenes.

\subsection{Concepciones sobre la práctica artística como investigación}

La idea del arte como una forma de investigación surgió en los años sesenta, a partir del arte conceptual. En esta época los artistas se opusieron a la visión del arte como una producción aislada de la historia, la política y el mundo social, y desde estos cuestionamientos proponen al arte y las experiencias artísticas como una forma de pensar y un saber cognitivo. Desde aquí que el arte moderno dejó de ser representacional para transformarse en autocrítico. Las estrategias de la crítica y la auto reflexividad fueron claves para generar nuevas comprensiones y significados artísticos. A partir de la época posmoderna, reflexión e investigación fueron aspectos que se entrelazaron con la práctica artística. Los artistas ya no buscaban sólo el resultado de la obra, sino comprender el proceso crítico (Wesseling, 2011).

Las propuestas de comprender a la práctica artística como una forma de reflexión e investigación, ha invitado a los propios artistas a teorizar sobre su práctica artística. Sullivan (2010) defiende este posicionamiento, al señalarnos en primer lugar que las artes visuales cumplen un rol importante en los contextos socioculturales y educativos, ya que las formas de saber artísticas nos ayudan a comprender el mundo en que vivimos. Desde aquí propone a la práctica artística no sólo como una forma de interpretar y representar, también como una manera que nos permite comprender aspectos, situaciones o experiencias de la vida cotidiana de una forma que otras tradiciones o disciplinas de investigación no pueden. En este sentido, el autor plantea que el trabajo imaginativo e intelectual de los artistas es una forma de investigación, ya que las formas de presentar, encontrar y de analizar la información produce un tipo de conocimiento que es transformativo, es decir, que tiene el potencial de cambiar la forma en que vemos y pensamos para mostrarnos nuevas formas de comprender (Sullivan, 2011). Desde esta afirmación, señala que la investigación que los artistas 
desarrollan en estudios, galerías, internet, comunidades, etcétera, son formas de investigación basadas en su práctica y que construyen nuevos conocimientos y comprensiones.

En este sentido, si uno de los objetivos de cualquier tipo de investigación cualitativa es generar nuevos conocimientos, también es factible pensar que existen diversas maneras y caminos para lograrlo, siendo la práctica artística una forma visual, plástica, creativa y crítica de investigación, que busca crear comprensiones y criticar el conocimiento. Desde este mismo lugar, Borgdorff (en Sullivan, 2010:79) señala que "la práctica artística califica como investigación si su objetivo es expandir nuestro conocimiento y comprensión al conducir una investigación original en y hacia los objetos visuales y procesos creativos". Además, la práctica artística como una forma reflexiva de investigación, genera un tipo de conocimiento creativo que tiene la capacidad de transformar nuestras formas de comprender, ya que sus objetivos, más que representar y confirmar una realidad son provocar, desafiar e iluminar (Sullivan, 2010).

Por otro lado, es importante considerar a la práctica artística como un tipo de investigación que es transformativa. Esto significa que la creación de conocimiento en las artes visuales constantemente genera cambios y nuevas comprensiones de nosotros mismos y del mundo. Las imágenes que vamos creando pueden comunicar nuevas ideas y miradas, concebir nuevos significados desde su descripción, representación, expresión o forma simbólica. En este proceso de creación, la práctica reflexiva es un elemento fundamental. Este proceso de pensar y repensar es lo que nos permite generar un tipo de conocimiento que nos ayuda a entender el mundo en que vivimos, nos permite aprender cómo le damos sentido y generar nuevos significados sobre aquello que no sabemos para develar nuevas verdades (Sullivan, 2010).

Esto lo logramos a partir de la práctica reflexiva que desarrollamos en el proceso artístico. "La práctica reflexiva es un tipo de actividad investigadora que utiliza diversos métodos para trabajar en contra de las teorías y prácticas existentes y ofrece la posibilidad de ver el fenómeno de nuevas maneras" (Sullivan, 2010: 110). Un artista-investigador reflexivo cuestionará contenidos y contextos mientras que las situaciones problemáticas se develan. En este sentido no sólo se identifican problemas sociales, también se abren áreas donde los investigadores se vuelven sensibles al cambio. Este interés emancipatorio ofrece oportunidades para promover cambio artístico, social, político, educativo o cultural.

A partir de la importancia que Sullivan (2010) otorga al pensamiento en el quehacer artístico, identifica tres formas reflexivas que se desarrollan en los procesos artísticos:

1. Un tipo de práctica reflexiva del yo responde a un proceso de investigación que es orientado por intereses personales y por una visión creativa que implica estar abierto a conceptos alternativos y nuevas opciones imaginativas.

2. Respondiendo a una comprensión empírica, un artista-investigador reflexiona sobre la información que va descubriendo y recopilando para revisar las estrategias conceptuales que utiliza y considerar nuevos enfoques o nuevas lecturas de su práctica.

3. Por último, en la medida en que el artista logra interpretar su proceso de creación, el conocimiento que va generando implica generar un nuevo diálogo 
con la información y sus descubrimientos. Esto significa que los significados que logra generar dependen de su forma de debatir y discutir con el mismo proyecto de investigación.

Para concluir este apartado, será importante mencionar que las ideas que ha propuesto Graeme Sullivan (2010,2011) sobre 'práctica artística como investigación', han sido de gran ayuda para comprender el proceso personal de indagación artística, junto a los intereses académicos que se desarrollan en la tesis doctoral, provocando nuevas formas de comprender y cuestionar la identidad artista e investigadora. Por ello, en el próximo apartado se realiza un recorrido por la práctica artística personal, donde se compartirá el aporte e influencia de los estudios doctorales en la indagación artística.

\section{Recorridos por la práctica artística y de investigación académica}

Se comienza este apartado situando la práctica artística personal y compartiendo los intereses como investigadora académica, ya que para comprender el problema principal de este artículo -el tránsito entre las identidades artista e investigadora académica- se hace necesario comprender los posicionamientos y recorridos que llevan a dichos cuestionamientos.

Desde el lugar de una artista visual se pueden contar dos aspectos fundamentales sobre una práctica artística: la técnica que se experimenta y la línea de investigación. En el quehacer artístico que se presenta, la acuarela se ha transformado no sólo en una técnica o un medio de expresión visual, sino en un proyecto. En esta práctica, el interés por construir retratos, enfocados principalmente en el gesto de la mirada, es el hilo conductor que permite comprender visual y plásticamente cómo el ser humano conforma su identidad. En esta indagación artística, retratar a otro/a no se limita en simplemente representarlo, sino conocerlo desde los diversos encuentros y desencuentros que se establecen, para comprender sus posibilidades, lo que conlleva un proceso que es tanto técnico como reflexivo e introspectivo. Bracha Ettinger (2012) ha señalado que pintar es preguntarse, y preguntarse conlleva un proceso de reflexión. El proceso de interpretar y representar a otros/as desde la acuarela ha permitido transitar entre la dilución del agua, el juego de capas y transparencias, como metáfora del cómo nos conformamos desde los múltiples yoes, historias y relatos. Durante este transcurso se re-interpreta y re-construye el rostro de un individuo dialogando con su historia. Este proceso es lo que Donald Schön (1992) ha llamado metafóricamente 'conversación reflexiva con los materiales de una situación' y hace alusión a cómo, a medida que se va pintando se puede pensar en reorganizar lo que se va haciendo. Es decir, a través de esta reflexión en acción no sólo se puede ser consciente de las direcciones del pincel o de los colores que se utilizan, sino también cuáles son los significados, o mejor aún, el o la artista puede ir reflexionando sobre la relación que posee con ese individuo.

Para continuar el relato sobre el desarrollo de esta práctica artística, se puede señalar que estas reflexiones se enriquecieron tras concluir el máster en Artes Visuales y Educación, cursado en la Universidad de Barcelona el año 2012, a partir del cual los diversos aprendizajes y cuestionamientos teóricos fueron cobrando sentido en 
esta práctica artística. Ese año de estudio implicó el aprendizaje teórico de diversas metodologías y perspectivas de conocimiento (investigación narrativa, pedagogías críticas, construccionismo, etcétera), las que en un principio fueron generando roces entre el modo de ser artista y académico/a, o bien, entender el mundo como artista o académico/a. Se experimentaron intensas horas de lecturas, las que poco a poco fueron cuestionando la formación de artista visual, y sobre todo, el lenguaje de expresión más cercano e innato, el cual se relacionaba más con la pintura o el grabado y no con la escritura. Como artista visual, la manera de comprender el mundo estaba más relacionada con la experiencia práctica, estética, experiencial y sensorial.

A pesar de ello, estos estudios permitieron comprender la escritura no sólo como un medio para organizar o transmitir ideas. A través de este proceso de formación se comprendió que los seres humanos se conforman de y desde relatos de experiencia (Clandinin y Connelly, 1990, 1994, 1995, 2000), lo que presentó a la narrativa como un nuevo lenguaje de expresión para contar a otros, nuevas formas de ver e interpretar el mundo. La narrativa, como una manera de abrir y compartir las vidas, permite organizar, dar coherencia y significado a las experiencias que se viven para mostrar y comprender quiénes somos. A partir de todo esto, la narrativa se ha presentado como una reconstrucción particular y consciente de la experiencia, la que mediante el proceso reflexivo da significado a lo vivido y permite configurar la construcción social de la realidad (Bolívar, 2002).

A partir de re-comprender la escritura, resurgió la necesidad de retomar la práctica artística: la pintura, los retratos y la acuarela, pero esta vez la narrativa sería un nuevo elemento que entraría en la indagación y práctica artística personal. Si narrarse es una forma de comprenderse, entonces la narrativa sería una herramienta que ligada a la acuarela, también permitiría comprender cómo se conforma la identidad en los individuos.

Desde estas nuevas ideas no fue complejo pensar cómo se retomaría la práctica artística, ya que todo lo que se había aprendido ese año en el máster había despertado muchas preguntas que inevitablemente gritaban con euforia que fueran trasladadas a un nuevo medio de representación. Las teorías feministas, o más bien, la noción de mujeres estaba muy latente en los aprendizajes de ese año, por lo que se comenzó a reflexionar cómo y desde qué lugar se podían trasladar estos nuevos aprendizajes al campo artístico. Se inició el proceso centrado en las mujeres docentes. A través de los diversos relatos reflexivos personales y el trabajo con la acuarela, se intentó dialogar con y desde los diversos textos que se habían repasado ese año. Al igual que Regina Cortina y Sonsoles San Román (2006), se buscó cuestionar la tradicional idea que asocia a las mujeres maestras como 'seres de estrato social bajo, con bajas remuneraciones y faltas de autoridad y disciplina debido a sus características maternales y amor incondicional a los niños'. Temas de este tipo, quizás más ligados a un feminismo radical, fueron los que se comenzó a desarrollar en las indagaciones artísticas. La escritura comenzó a ser un apoyo y un medio de expresión crítico, mediante el cual se intentaba dialogar entre las imágenes y los pensamientos personales sobre las mujeres docentes.

La figura 1 muestra cómo comencé acercarme al tema de mujeres a través del arte. En estos trabajos se retrataba a compañeras del master realizado el 2012, y se buscaba 
cuestionar el rol de la mujer mediante elementos que, como flores, coronas y aureolas, pusieran en juego la historia de las mujeres en la sociedad patriarcal. Luego, a partir de la figura 2 señalo cómo, el nuevo elemento de la escritura, sustituye los elementos anecdóticos anteriores (flores, coronas, aureolas), formando parte importante de las indagaciones artísticas, como espacio para relatarme, y a su vez, relatar mi relación con aquellas mujeres retratadas.
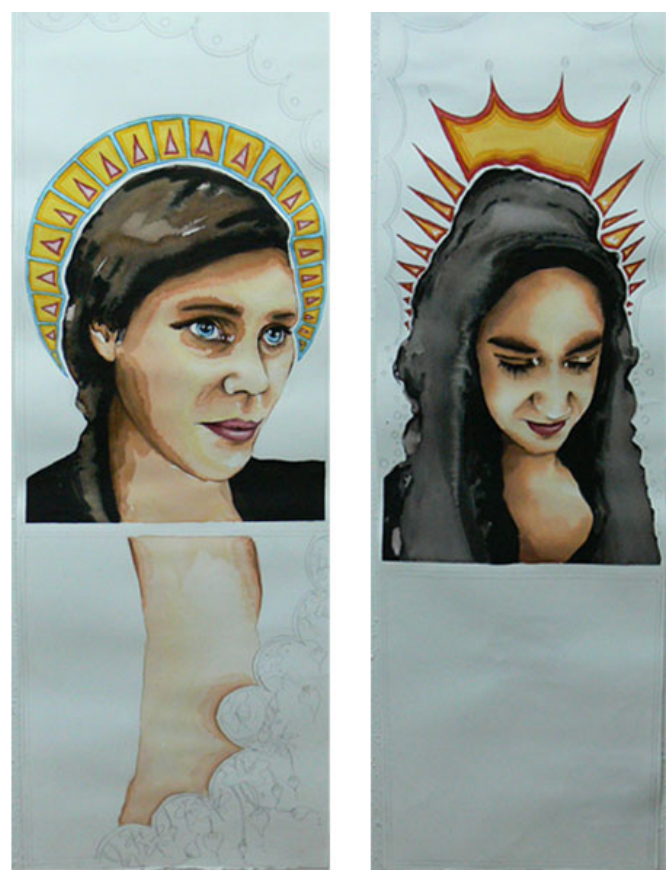

Figura 1. (2012) Sin titulo. Acuarela sobre papel.

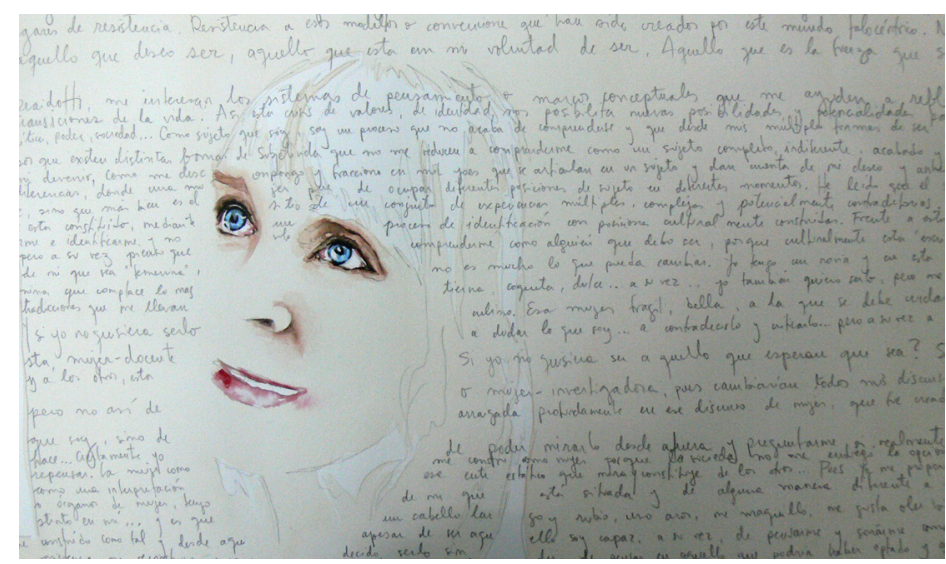

Figura 2. (2012) Sin título. Acuarela sobre papel. 
Actualmente se cursa el doctorado en "Artes y Educación". El título de la tesis doctoral que se desarrolla es "Profesora de Artes Visuales en Chile. Comprender el tránsito entre la práctica artística y docente, desde experiencias narrativas". Como se ha mencionado anteriormente, en este escrito no se busca explicar la investigación de doctorado, sino reflexionar cómo a partir del interés por la narrativa y el tema "mujeres artistas docentes", el rol que se cumple como investigadora se ha ido construyendo en conjunto con el rol e identidad como artista. Para ello, a partir del tema de la investigación doctoral, donde se busca comprender y visibilizar los saberes docentes en relación a la experiencia vivida y narrada de mujeres chilenas, artistas-docentes y del interés artístico por la construcción de retratos, se ha comenzado el proyecto de investigación artístico (paralelo a la investigación doctoral), llamado "Diálogos con mujeres artistas docentes". Este es un proyecto en construcción, donde se ha vinculado ambas prácticas (de investigación doctoral y la artística) para generar una serie de narrativas visuales. A través de diversos intercambios narrativos, con cinco mujeres artistas docentes, se ha compartido narrativamente cómo se perciben en su práctica artística y docente hoy. Desde estos relatos han sido re-interpretadas para, desde gestos pictóricos, narrativos y digitales, buscar nuevas formas de visibilizar y comprender sus modos de ser y estar. Este proyecto se ha transformado en un espacio para indagar, desde las artes, sus relatos de experiencias entrecruzados con los personales. Este proceso, a su vez ha generado un espacio para cuestionar la propia identidad como artista al verla entrecruzada con los intereses académicos y de investigación.

A partir de lo señalado, la práctica artística que se narra, se ha ido reformulando para dar paso al tipo de práctica artística que Sullivan (2010) ha llamado "Hacer en Sistemas". Como se ha señalado anteriormente, en este tipo de prácticas los artistas buscan crear nuevas formas visuales de representación que trasciendan las disciplinas establecidas para vincularse con otras perspectivas o áreas. Esto, con el fin de mostrar nuevas formas de conceptualizar y comprender las formas y estructuras visuales.

En el tipo de práctica artística que se narra se han comenzado a establecer vínculos entre el retrato, la acuarela y la narrativa, con experiencias de otras mujeres, artistas y docentes. Esto ha llevado a que, como artista, se abandone ese posicionamiento fijo de la disciplina artística, para abrirse a nuevos espacios y perspectivas de conocimientos. Se ha dejado de pensar en la indagación artística como una práctica cerrada y monótona, para que, en conjunto con otras disciplinas (como la investigación narrativa, la fenomenología, el feminismo, la educación, etcétera) pueda promover nuevas formas de comprensión.

\section{Comprender la práctica artística como investigación en el proyecto "Diálogos con mujeres artistas docentes"}

Para relatar cómo esta práctica artística se ha ido articulando como investigación, se describirá más en profundidad este proceso, para dejar entrever cómo la importancia de éste radica en su proceso y no en su resultado. En este sentido, lo primero que se debe tener en cuenta es que este trabajo es un proceso que se encuentra en construcción. Por otro lado, demás está comentar desde dónde surgió este proyecto, pero sería importante recalcar dos aspectos. 
Primero, es importante aclarar que éste no constituye parte de la investigación doctoral, sino que son exploraciones artísticas que surgen desde el tema de investigación. A partir de la creación de estas narrativas visuales, como artista se busca comprender, generar sentido, visibilizar, dar significado y dialogar con las experiencias de otras mujeres, artistas y docentes, desde lo visual (Bach, 2007).

En este sentido, si bien en la investigación doctoral y también en la artística se desarrolla el tema "mujeres artistas docentes", las participantes que inspiran este proyecto artístico, de momento, no son las cuatro profesoras con quienes se desarrolla la tesis. Es decir, no se habla ni refiere a las mismas mujeres. Esto se debe a que las cinco mujeres artistas que forman parte de este proyecto poseen una relación cercana con la artista, lo que ha permitido un diálogo y acercamiento. Este aspecto cobra mucha importancia ya que desde la experiencia como artista, acercarse a interpretar la vida, gesto, rostro y mirada de un individuo desde la pintura, implica conocer esa vida, gesto, rostro y mirada. Desde aquí que pintar no es sólo un acto mecánico y técnico de reproducción, sino que en la práctica artística que se señala, es una acción de conexión profunda, en la cual se entra en la historia del retratado para conectarse con ese sujeto desde la reflexividad, aspecto que Schön (1998) llama 'reflexionar sobre nuestro conocimiento en acción'. En este sentido, las cinco colaboradoras de esta indagación se identifican como mujeres, artistas y docentes y desde aquí este proyecto se ha centrado por comprender visualmente cómo dan sentido a su experiencia entre las artes y la educación. Para ello, en primera instancia se le pidió a cada colaboradora que narrara, desde el género o forma literaria que quisiera (ensayo, carta, recuerdo, anécdota, cuento, etc.) cómo se percibe como mujer, artista y docente. Estos relatos permitieron entrar en sus historias para, como investigadora preguntarse, ¿desde dónde uno se coloca como investigador/a y ¿cómo enfrentar esas historias desde las artes?

Llegados a este punto, es importante relatar el proceso de trabajo y las decisiones que se fueron tomando en este camino de investigación, ya que el objetivo de este artículo no sólo es develar la posición como artista e investigadora "in-between", sino sobre todo subrayar que todas estas decisiones o cuestionamientos que se han enfrentado, son los aspectos o dilemas que se hacen presentes en el diálogo entre las identidades.

Si bien la idea inicial del proyecto era hacer una gran serie donde se presentaran a las cinco colaboradoras, el proceso de "ir haciendo" permitió comprender que cada diálogo implicaba diversas formas de acercamiento. Esto llevó a repensar las estrategias de representación artística, para comenzar a realizar series originales, es decir, diálogos personales con cada mujer, artista y docente. Con cada una de ellas se fue conformando una serie diferente, única y nunca acabada, donde digitalmente se exploró la posibilidad de generar diversas historias visuales ¿Qué significa esto? Cada sentido de ser mujer, artista y docente es diferente, lo que ha llevado a dialogar de manera muy diversa con cada una.

En este sentido, cada serie muestra el proceso de cómo se han realizado los retratos. Cada narrativa visual cuenta, tanto visual como textualmente, un proceso distinto de comprender sus palabras y las reflexiones personales. Como plantea Sullivan (2010), las artes visuales implican un tipo de pensamiento imaginativo que nunca es fijo, ya que siempre transitamos entre lo sabemos y no sabemos. En este sentido, estos 
proyectos son procesos de reflexividad inacabados.

La pregunta que surge constantemente es ¿cómo dialogar con sus relatos en el momento que se van creando las imágenes? A partir de estos relatos, como evidencias de sus historias, se genera una conversación durante el proceso de retratarlas. Así, la experiencia de retratarlas se transforma en un espacio de pensamiento. Durante estas reflexiones se pintan sus rostros, y son observadas para conversar íntimamente. Se dibuja, se escribe, se pinta, se escribe, y pinta, como actos que se van tejiendo de manera espontánea y consecutiva. Se dibuja y piensa en ellas, se escriben sus pensamientos y se escribe sobre ellos, se pintan los pensamientos y se vuelve a escribir para reafirmar los diálogos que se van generando. Un diálogo a tres voces. La voz de sus experiencias, la voz de cómo sus experiencias interpelan la experiencia de la artista y la voz de los retratos, siendo éstos una manera de mirarlas mientras se dialoga. Estas conversaciones son las que llevan a crear un nuevo relato que es escrito y pictórico.

Este proceso se ha convertido en un hacer y deshacer, y justamente este proceso es el proyecto "Diálogos entre mujeres artistas docentes". Cuando se alude a esta investigación artística como un proceso, se refiere a que los resultados son lo último que se espera encontrar, ya que como ha enseñado Janneke Wesseling (2011), el trabajo artístico no es un producto acabado ni el resultado acabado de un pensamiento artístico. Por el contrario, es el estadio intermedio de un proceso de pensamiento que nunca se acaba. Debido a ello en este artículo no se presentan resultados artísticos, sino que lo que se señala es un proceso donde cada imagen que se mueve es debido a un proceso de pensamiento, cada frase que se escribe es pensando en sus historias, en lo que han contado y en cómo se busca relatarlas.

En las siguientes páginas se profundiza en una de las cinco narrativas visuales, para compartir con mayor detalle cómo se ha ido dialogando con los relatos de estas mujeres.

\subsection{El proceso de construcción de "Diálogos con mujeres artistas docentes. Elisa"}

Se invitó a Elisa a formar parte del proyecto artístico "Diálogo con mujeres artistas docentes" ya que su modo de percibirse como mujer artista y docente había marcado un sello en la propia experiencia. Desde aquí se interesaba comprender de qué modo su propia experiencia podía ser interpretada visual y narrativamente. Para ello se le pidió que relatara, del modo que quisiera, cómo se percibía como mujer, artista y docente. A continuación se señala el escrito que compartió:

"Ser Mujer, Ser Artista, Ser Profesora...

De las tres, ser mujer es lo único que no elegí! pero es una de las que más valoro...

De las tres, ser artista es la que me hace más feliz y la que se conecta más con mi interior...

De las tres, ser profesor es la que más me cuesta pero con la que me siento mejor persona...

De las tres, las tres creo que son muy difíciles de vivir en un país como Chile...

De las tres, no dejaría de ser ninguna...

De las tres, es muy dificil priorizar una sobre la otra porque las tres me conforman de igual manera y me siento orgullosa de ser mujer, de ser artista y de ser profesora". 
A partir de este pequeño relato se comenzó a re-significar la experiencia con Elisa. Entrecruzar su historia con la personal fue el proceso que llevó a interpretarla desde la pintura para construir la narrativa visual. En este sentido, el proceso de pintura no fue un acto lineal, cerrado, monótono e inconsciente. Por el contrario, cada momento del proceso de dibujar y pintar cobraba sentido cuando se era consciente que se dibujaba su historia entrecruzada con los diálogos y pensamientos personales. Así, cada capa de pintura en acuarela implicaba detenerse a reflexionar sobre su modo de percibirse, y cómo ello interpelaba y colocaba la posición personal como mujer, artista e investigadora. Fue un proceso de pensar en cómo sus palabras se habían manifestado en nuestra historia, en su modo de enseñar las artes y la docencia.

Así, la narrativa visual se divide en cuatro fragmentos ordenados de arriba hacia abajo (Figura 2). En el primer apartado, se introduce y sitúa la narrativa visual y se presenta a Elisa como la mujer, artista y docente a quien se interpreta. La segunda parte, titulada "El proceso de diálogo", se comparte su relato para señalar la importancia que tuvieron sus palabras como punto de partida para comenzar el proceso de representación e interpretación. El tercer fragmento, el cual es el más largo, esconde el proceso de pintura y de conversación íntima con Elisa. Se va desvelando paso a paso tanto el proceso de capas con la acuarela como el proceso de reflexión de cada momento. Por último, en la parte inferior se señala una leyenda con tres iconos. Cada uno señala un estado en relación al proceso de pintura. Por ende, cada etapa del tercer fragmento tiene un ícono que muestra, paralelo al proceso de reflexión, el estado personal en relación al proceso técnico de pintar. Fue importante señalar esta leyenda ya que durante el momento de pintar existen instancias de mayor o menor dificultad, las cuales influyen en lo que cada artista pueda ir reflexionando y su modo de consciencia en el proceso.

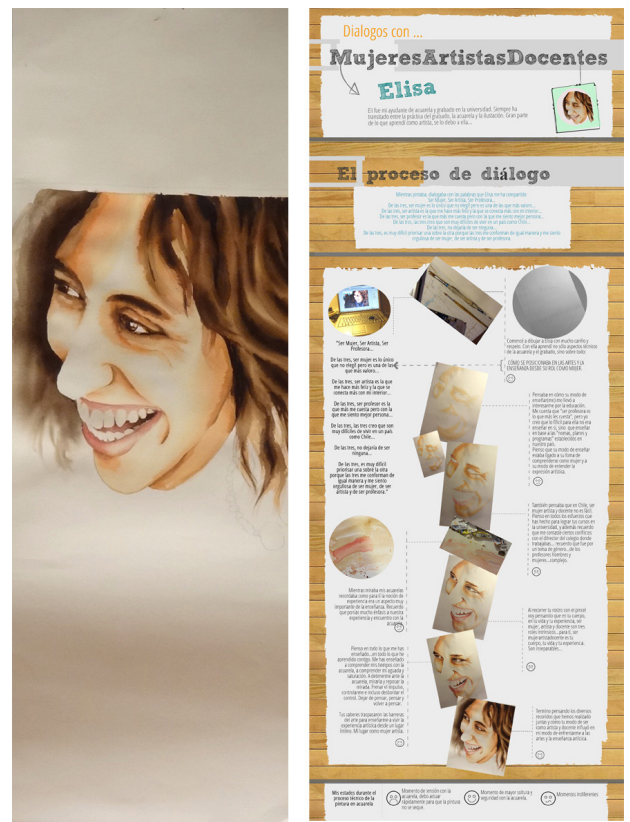

Figura 3. (2013) "Diálogos con mujeres artistas docentes. Elisa”. Acuarela y narrativa visual. 


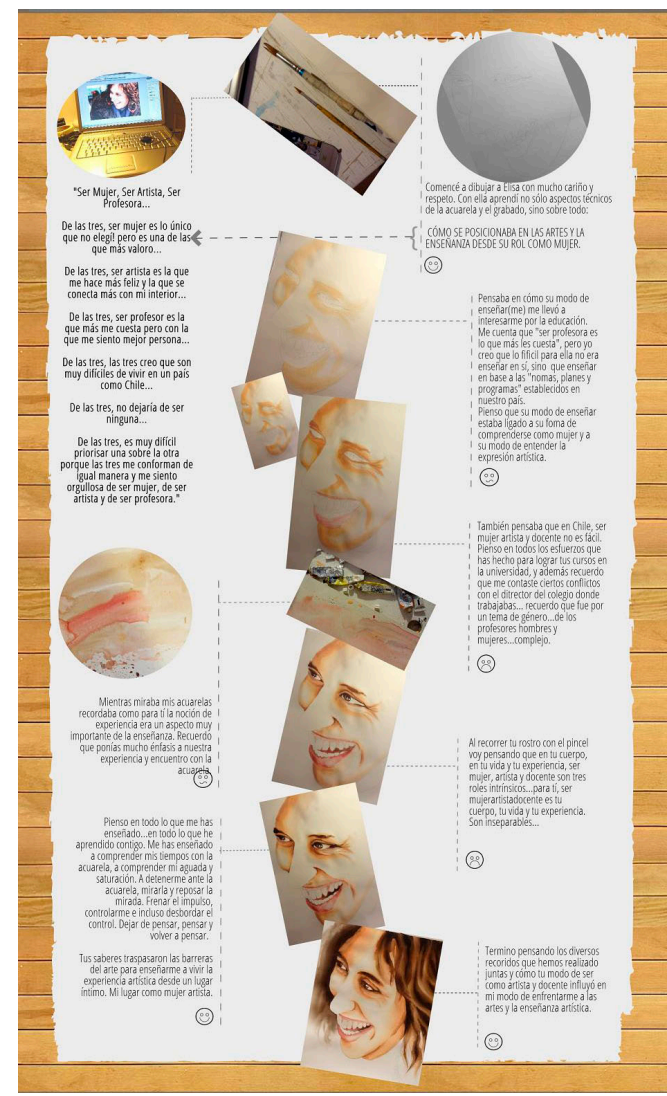

Figura 4. (2013) Detalle de narrativa "Diálogos con mujeres artistas docentes. Elisa". Fotografía y photoshop.

\section{Transitar entre la práctica artística y de investigación. Comprender las múltiples identidades in-between}

Sería ventajoso iniciar este apartado recordando que hoy en día el rol del artista se ha ampliado. Se habla del artista tanto como un creador, crítico, teórico, profesor y activista, siendo todas estas actividades las que conforman su práctica artística (Sullivan, 2010). Todas estas funciones que cumple le permiten construir una práctica que no se caracteriza por ser uni-dimensional, sino que se realiza en y desde múltiples formas. Así, el espacio entre la teoría y la práctica se transforma en un espacio de creación artística y de investigación, que traspasa los límites establecidos por los cánones. El artista como teórico, utiliza el poder transformativo de las artes como una práctica interactiva y de resistencia, y como significado del cambio cultural e individual.

A partir de las reflexiones de Sullivan sobre la práctica artística como investigación y el proyecto artístico que se ha descrito, comenzó el cuestionamiento de si realmente existe o "debiera existir" un límite entre la identidad como artista e investigadora 
y qué significa que ambos roles dialoguen para desarrollar en conjunto estos cuestionamientos personales y académicos.

Durante este proceso, Kan Koon (2009) ha sido una académica que ha iluminado estos cuestionamientos. Esta autora también ha contado que, debido a que primero se formó como artista creativa, ha tenido que buscar la manera de complementarlo con su rol como académica. A través de su forma de cuestionar y dialogar sus luchas como artista-académica ha permitido comprender cómo ella se ha preguntado el significado de ser una artista-académica desde el punto de vista de ser una mujer asiática. Su posicionamiento también ha planteado la pregunta ¿qué significa formarse como mujer investigadora, sin dejar de lado el rol como artista? La autora habla de abrir un paso -o espacio se podría pensar- entre las imágenes y las palabras, para dar cabida a las diversas dimensiones de su existencia como mujer, artista y académica asiática.

En el caso de la práctica artística que se ha descrito, generar un diálogo entre las imágenes y las palabras, es una manera de transitar y multidireccionar lo que se va reflexionando. En este sentido, aquello que se reflexiona no es la pintura independiente del texto, o el texto una reflexión sobre lo que se pinta, sino que se intenta que ambos gestos, el de pintar y escribir, sean una manera complementaria de dialogar con la experiencia personal y la de otras mujeres, artistas y docentes. En este sentido, escribir se ha transformado en una práctica artística y a su vez académica. Se escribe no sólo para explicar, sino también para comprender y cuestionar aquello que se piensa y pinta. El texto, como un aspecto que representa la postura o pensamiento académico y de investigadora, dialoga con la imagen pictórica, que toma relación con un ímpetu artista. El texto, como esa obsesión por intentar comprenderse a uno mismo y a otros/as, desde diálogos y relatos, y la imagen, como esa otra obsesión por el rostro, por lo que dice y muestra la mirada del otro/a.

Ahora bien, en relación a lo anterior, un desafío importante como artistas es la pregunta ¿cómo sostener este proceso para que sea una experiencia artística? Si John Dewey (1934) propone que en una experiencia artística dejamos "volar" nuestra mente para vivir esa experiencia de creación, vale la pena preguntarse entonces si acaso la escritura se mostraría cómo un gesto de control. Si la pintura es aquello irracional y la escritura aquello racional, que busca explicar y entender, ¿cómo dialogan sin que una prevalezca sobre la otra? A través de estos pensamientos y cuestionamientos se señalan los desplazamientos entre las artes y la investigación académica. Las narrativas visuales que se han ido conformando en el proyecto "Diálogos con mujeres artistas docentes", son, a modo de proceso, una nueva forma de contar historias que van más allá de sólo escribir un texto y de pintar un retrato. Se intenta contar estas historias desde el lugar de las artes, pero también desde una posición como académica. En este sentido, la escritura, como aquello que se ha aprendido desde la experiencia y rol como investigadora en formación, transita hacia la práctica artística para fundirse con la creación pictórica. En este proceso las palabras que se escriben no buscan sólo interpretar y comprender acciones o pensamientos, sino también son un medio de expresión.

Por último, este proceso ha llevado a posicionarse como mujer, artista e investigadora in-between, en vez de sólo buscar establecer un espacio determinado o rol fijo. Es decir, en un espacio-entre, ya que nunca se actúa completamente como 
artista o totalmente como investigador/a. Constantemente un individuo puede moverse y transitar entre estos dos roles. A pesar de que ambos puedan cuestionarse o en algunas instancias estar en tensión, ambas prácticas pueden trabajar en conjunto y permiten desarrollar intersecciones como mujer, artista e investigadora.

\section{Conclusiones}

En este artículo se han compartido los caminos de la práctica artística personal, describiendo parte del proyecto "Diálogo con mujeres artistas docentes", para reflexionar cómo la identidad como artista e investigadora, está constantemente fluyendo y entretejiéndose mutuamente. Desde este lugar, no se busca situar una identidad fija e inamovible, al contrario, es interesante comprender cómo ambas practicas (la artística y de investigación doctoral) pueden nutrirse, interpelarse y hasta cuestionarse. Se transita entre diversos roles y disciplinas para mostrar cómo la pasión artística traspasa los intereses académicos y por otro lado, cómo los intereses académicos se transforman en un hacer y búsqueda artística. Por otro lado, reflexionar sobre el proceso de conformación como investigadora académica, ha servido para mostrar lo importante que es comprender que en ningún tipo o forma de investigación se pueden eludir las propias circunstancias (Welier, 1988). Frente a esto, ha sido importante comprender que el sentido de ser personal no queda eludido ni de los propios intereses artísticos ni de la investigación doctoral. Más bien intentan dialogar y, es en ese diálogo cuando se comienza a transitar entre ambas disciplinas $\mathrm{y}$ formaciones.

Para finalizar se señala lo importante que fue comprender cómo la práctica artística comenzó a tomar cuerpo, fuerza, y un mayor sentido cuando los intereses y aprendizajes de las disciplinas académicas comenzaron a introducirse en las indagaciones artísticas. Fue como si las disciplinas de las ciencias sociales comenzaran hacer un nido que sostuviera, cuestionara y tensara el quehacer artístico. Este proceso llevó a que la práctica artística se transformara en un espacio abierto, crítico y reflexivo, desde el cual se comenzó a buscar nuevos modos de visualizar e interpretar la experiencia humana. Esto es lo que Sullivan $(2010,2011)$ ha señalado incansablemente como 'práctica artística como investigación'. A partir de aquí, se puede señalar que las cinco narrativas visuales que se han ido conformando, no sólo actúan como un modo de representar la realidad de cada mujer, artista y docente, sino sobre todo son una manera visual y creativa de interpretar experiencias de la vida cotidiana, que de la misma manera, otras tradiciones o disciplinas de investigación no pueden. A su vez, estas narrativas visuales muestran un tipo de conocimiento que es transformativo, es decir, cambian la forma en que tradicionalmente se suele representar, ver o pensar la realidad de mujeres, artistas y docentes para mostrar nuevas formas de comprender sus experiencias. Así mismo, estas narrativas visuales son otro modo de criticar o cuestionar las convenciones que las tradiciones hegemónicas han establecido sobre las mujeres artistas y las mujeres docentes. En este sentido, estas cinco narrativas visuales y sobre todo la que se señala a modo de ejemplo, más que representar y confirmar una realidad son un modo de provocar y desafiar, para mostrar desde imágenes visuales y escritas otras formas de ser en el mundo. 


\section{Referencias}

Bach, H. (2007) Composing a Visual Narrative Inquiry. En Clandinin, J. (2007) Handbook of Narrative Inquiry. Mapping a Methodology. (pp. 280-307) California: Sage.

Bolívar, A. (2002). “¿De nobis ipsis silemus?”: Epistemología de la investigación biográfico-narrativa en educación. Revista Electrónica de Investigación Educativa, 4(1), 1-26.

Cortina, R., San Román, S. (2006) Women and Teaching. Global Perspectives on the Feminization of a Profession. United States of America: Palgrave Macmillan.

Clandinin, J. \& Connelly, M. (1990) Stories of experience and Narrative Inquiry. Educational Researcher, 19(5), 2-14.

Clandinin, J. \& Connelly, M. (1994) Teachers telling stories. Teacher Education Quarterly, 21(1), 145-158.

Clandinin, J. \& Connelly, M. (1995) Relatos de experiencia e investigación narrativa. En Larrosa (Ed) Déjame que te cuente. Ensayos sobre narrativa y educación. (pp. 11-59) Barcelona: Laertes.

Clandinin, J. \& Connelly, M. (2000) Narrative inquiry: experience and story in qualitative research. California: Jossey-Bass.

Dewey, J. (1934) Art as experience. New York: Perigee Books.

Espot, R. (2006) La autoridad del profesor. Qué es la autoridad y cómo se adquiere. Madrid:Praxis

Ettinger, B. (2012) The Sublime and Beauty beyond Uncanny Anxiety. En Dombois, F., Meta Bauer, U., Mareis, C., Schwab, M. Intellectual Birdhouse. Artistic Practice as Reseach. (pp. 189- 213) Londres: Koenig Books.

Kan, K. H. (2009). Caught in the betwixt-and-between: Visual narrative of

an Asian artist-scholar. International Journal of Education \& the Arts, 10(29). Retrieved [date] from http://www.ijea.org/v10n29/.

Schön, D. (1992) La formación de profesionales reflexivos. Hacia un nuevo diseño de la enseñanza y el aprendizaje en las profesiones. Barcelona: Paidós.

Schön, D. (1998) El profesional Reflexivo. Cómo piensan los profesionales cuando actúan. Barcelona: Paidós.

Sullivan, G. (2010) Art Practice as Research. Inquiry in Visual Arts. London: SAGE Sullivan, G. (2011) The Artist as Researcher. New Roles for New Realities. En Wesseling, J. See it Again, Say it Again: The Artist as Researcher.(pp.79-101) Amsterdam: Valiz Antennal.

Weiler, K. (1988) Women Teaching for Change. Gender, Class and Power. EE.UU: Garbey Publisher.

Wesseling, J. (2011) See it Again, Say it Again: The Artist as Researcher. Introduction. (pp. 1-15) Amsterdam: Valiz Antennal. 
